\title{
Operation scheduling of prosumer with renewable energy sources and storage devices
}

\author{
S. M. Souza ${ }^{1,2}$, M. Gil ${ }^{1}$, J. Sumaili ${ }^{1}$, A. G. Madureira ${ }^{1}$, J. A. Peças Lopes ${ }^{1,3}$ \\ ${ }^{1}$ INESC TEC, Porto, Portugal \\ ${ }^{2}$ ELETROBRAS, Rio de Janeiro, Brasil \\ ${ }^{3}$ FEUP, Porto, Portugal \\ suzana.souza@eletrobras.com, mariana.g.cunha@inesctec.pt, jean.sumaili@inesctec.pt, andre.g.madureira@inesctec.pt, jpl@fe.up.pt
}

\begin{abstract}
The reduction or elimination of incentives for the installation of decentralized generation directly at the customers' premises, favoring self-consumption, can bring significant changes for distribution network operation. According to the new Portuguese law, injection of energy into the distribution grid is discouraged since prosumers receive only 90\% of the energy cost in the Iberian Energy Market. In order to lower energy bills, the possibility of storing excess energy is being considered as a possible solution. In this paper, an optimization framework is proposed to model the operation of consumers with renewable-based Distributed Generation (DG) and storage capacity and assess their aggregated effect at the level of the MV grid using a multi-temporal Optimal Power Flow (OPF). The proposed algorithm is then tested in a real Portuguese MV network to evaluate its performance. Finally, a financial viability analysis is performed considering the installation of small $\mathrm{PV}$ generators and storage devices at the residential level.
\end{abstract}

Index Terms--Interior-point Method, Multi-Temporal OPF, Storage Devices, Self-Consumption

\section{INTRODUCTION}

The integration of Dispersed Generation (DG), particularly those technologies based on variable Renewable Energy Sources (RES) such as solar photovoltaic (PV), are causing a change of paradigm in power systems [1]. In a recent past, the integration of DG in electrical networks was heavily subsidized in order to foster the technological development and the growth of RES. More recently, the reduction or even elimination of these incentives for decentralized production activity for consumers who have their own generation units (prosumers), thus prioritizing self-consumption, brought additional challenges concerning the management of consumption and generation.

For instance, according to the new Portuguese law (Decree-Law no. 1532014) by injecting energy into the distribution network, the prosumers receive only ninety percent of the energy cost from the Operator of the Iberian Energy Market (OMIE). For this reason, ideally the injection of energy into the network should be minimal in order to reduce the electricity bill for the prosumers. This measure is supposed to encourage self-consumption for domestic clients.
Due to this fact, the use of storage devices is being widely considered as an interesting solution. In particular, small battery units coupled to solar PV systems may be installed at consumer dwellings to enable the customer to manage his own energy consumption. The action of the storage device will enable reducing the injection in the grid from the PV system, through the displacement of this energy along the day i.e. by injecting only when the energy is needed most, and by charging when there is an excess of generation or the price of the energy are cheaper than in other periods. The changes caused in terms of network load profiles and corresponding changes in distribution network operation still need to be addressed in full.

Some papers can be found in the scientific literature that address the scheduling of PV self-consumption with storage for residential clients [2], [3]. Also in [4], a system for scheduling electric water heaters (thermal storage) in order to optimize PV self-consumption is proposed and validated.

In this paper, the operation of the distribution system for the day-ahead and for the case where consumers have their own generation units associated with a local storage device is modelled. This is done by formulating a multi-temporal OPF for the period of a whole day that takes into account the specific constraints introduced by the presence of the storage device including their State of Charge (SOC) limits as well as its charging and discharging efficiencies. The objective function considered here is the minimization of the electricity bill for the prosumers. The proposed algorithm was implemented in MATLAB and it was developed in such a way to make it as flexible as possible and easily enable adding/removing constraints and/or additional variables. In addition, a financial analysis concerning the installation of PV micro-generation together with storage devices at the level of residential consumers is performed. This enables assessing the viability of such an investment considering different scenarios.

This paper is organized as follows: section II presents the formulation of the optimization problem for the day-ahead; section III shows the financial viability analysis performed; section IV presents the case study for the presented optimization model and section $\mathrm{V}$ draws the main conclusions from the work performed. 


\section{Formulation Of The OPtiMiZATION PROBlem}

The proposed model is formulated as a unique optimization problem that considers the operation for a full day of 24 hours with hourly resolution. In this context, a multi-temporal OPF is developed and it is able to take into account consumers who have their own generation units and have storage devices for the management of the consumption and the generation.

A classical formulation for the OPF problem (given in [5]) was implemented in MATPOWER software developed in MATLAB. In this work, MATPOWER was used as the basic platform for developing the optimization problem and extend the formulation to a multi-temporal model, like the works in [6]-[8]. Moreover, not only the traditional constraints such as bus voltage limits, branch limits and generation unit limits were considered but also additional constraints introduced by the presence of storage devices.

The definition of the constraints related to the storage devices are presented next. From an energy balance point of view, the efficiency of the storage process needs to be considered. This includes discontinuity in the storage model and in the corresponding restrictions. In this paper, one proposes to model the storage device as four different elements with continuous behaviour: a load during the charging period $\left(P_{t}^{\text {load }} \leq 0\right)$, a generator for power injection $\left(P_{t}^{i n j} \geq 0\right)$ and two loads emulating the storage losses during the charging and the injecting periods of the battery, respectively $\left(L_{t}^{\text {load }} \leq 0, L_{t}^{\text {inj }} \leq 0\right)$.

Figure 1 illustrates the model implemented for the storage devices.

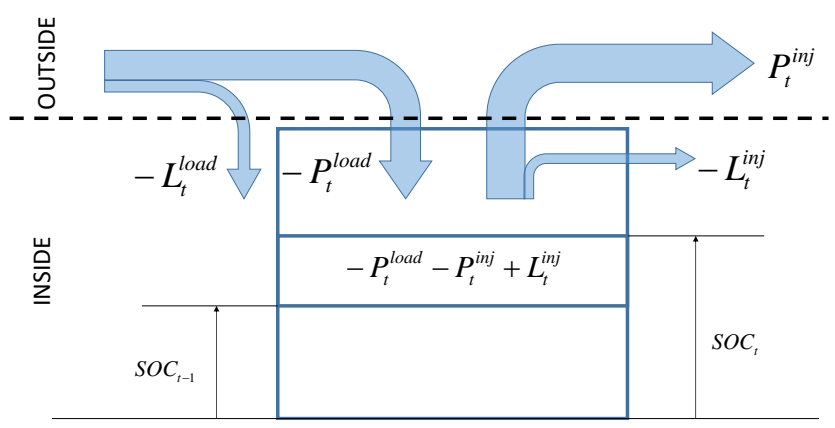

Figure 1 - Storage Device Model

Equations (1) and (2) describe the restrictions that represent the losses of the charging process and the losses of the injection process of the storage devices, respectively.

- Charging losses:

$$
L_{t}^{\text {load }}=\frac{\left(1-\varepsilon^{\text {charge }}\right)}{\varepsilon^{\text {charge }}} \times P_{t}^{\text {load }}
$$

- Injection losses:

$$
L_{t}^{i n j}=\frac{\left(\varepsilon^{\text {discharge }}-1\right)}{\varepsilon^{\text {discharge }}} \times P_{t}^{i n j}
$$

where:

$\varepsilon^{\text {charge }}$ is the charge efficiency,

$\varepsilon^{\text {discharge }}$ is the discharge efficiency,

$P_{t}^{\text {load }}$ is the charge power on time $t$,

$P_{t}^{i n j}$ is the injection power on time $t$,

$L_{t}^{\text {load }}$ is the loss during the charge on time $t$, and

$L_{t}^{i n j}$ is the loss during the injection on time $t$.

In order to consider the storage device for the management of the consumption and the generation of the consumers, it was also necessary to include the SOC for the storage devices as a variable. The value of the SOC for each time instant was considered as well as the interdependency between periods as described in (3).

$$
S O C_{t}=S O C_{t-1}-P_{t}^{l o a d}-P_{t}^{i n j}+L_{t}^{i n j}
$$

where:

$S O C_{t}$ is the state of charge on time $t$, and

$S O C_{t-1}$ is the state of charge on time $t-1$.

Other constraints associated with the SOC have also been introduced in the OPF. The limits for the SOC are shown in (4), where $S O C^{\max }$ is the upper bound and $S O C^{\min }$ is the lower bound of the state of charge.

$$
S O C^{\min } \leq S O C_{t} \leq S O C^{\max }
$$

The overall power balance of the storage device is presented in (5), where the injecting power, the charging power, the losses of injecting and charging are considered.

$$
P_{t}^{\text {global }}=P_{t}^{i n j}+L_{t}^{i n j}+P_{t}^{\text {load }}+L_{t}^{\text {load }}
$$

where:

$P_{t}^{\text {global }}$ is the balance representation of the storage device.

For the period of analysis, in this case operation of one full day, it was considered that the SOC at the end of the simulation period must be the same as the initial SOC. This leads to the following equation:

$$
\sum_{t=1}^{24} P_{t}^{\text {load }}+P_{t}^{i n j}+L_{t}^{i n j}=0
$$

The objective function considered, here, is the minimization of the electricity bill for the prosumers with a storage device associated. Therefore, electricity purchase costs were considered assuming that the clients have chosen a multi-period tariff as presented in Table I.

TABLE I. ENERGY TARIFF $(€ / \mathrm{KWH})$

\begin{tabular}{|c|c|c|c|}
\hline Periods & Peak Hours & Full Hours & Valley Hours \\
\hline Winter/Summer & 0.2106 & 0.1675 & 0.0978 \\
\hline
\end{tabular}

This tariff includes three different prices according to three time periods: peak hours, full hours and valley hours. The valley hours are, fundamentally, the hours of the night and on weekends where energy is the cheapest while peak hours are 
typically during the beginning of the night when people are home and are expected to have most appliances running and therefore, when energy costs are higher.

The remuneration for the injection of energy into the distribution grid must also be considered. The cost of this energy should follow the rules of the current Portuguese legislation, and is related to the closing price of the Iberian energy market, according to the new legislation related to selfconsumption. The remuneration of the injected excess energy is represented by (7):

$$
R_{U P A C}=E_{i n j, m} \times O M I E_{m} \times 0,9
$$

where:

$R_{U P A C}$ is the remuneration for the energy injected in the network in month $m$, in $€$;

$E_{i n j, m}$ is the energy injected in the network in month $m$, in kWh;

$O M I E_{m}$ is the arithmetic average of the daily price at the Operator of the Iberian Energy Market (OMIE) for Portugal (daily market) relative to the month $m$;

$m$ is the month of the reference for the electricity account injected in the network.

The arithmetic average of daily price at the Operator of the Iberian Energy Market (OMIE) for the year 2015 is presented in Table II.

TABLE II. THE OPERATOR ENERGY PRICE $(€ / \mathrm{KWH})$

\begin{tabular}{|c|c|}
\hline Month & $(\boldsymbol{€} /$ MWh $)$ \\
\hline January & 60.45 \\
\hline February & 53.00 \\
\hline March & 51.07 \\
\hline April & 53.55 \\
\hline May & 52.26 \\
\hline June & 60.29 \\
\hline July & 65.27 \\
\hline August & 58.64 \\
\hline September & 54.98 \\
\hline October & 54.29 \\
\hline November & 55.92 \\
\hline December & 57.33 \\
\hline
\end{tabular}

Considering that the remuneration for injecting energy into the grid is low, the tendency is to inject as minimum as possible into the distribution network. Thus, the storage device has a fundamental role in the operation of these systems, by smoothing the load profile.

Since one aims to minimize the consumer's electricity bill, the equivalent balance of these consumers must be represented. The optimization will be made via the cost of buying and selling associated with equivalent power consumption or injection into the network. Equation (8) represents the equivalent energy consumption and grid injection for a consumer with PV plant and storage device.

$$
P_{t}^{\text {prosumer }}=P_{t}^{\text {load }}+P_{t}^{P V}+P_{t}^{\text {global }}
$$

where:

$P_{t}^{\text {prosumer }}$ is the balance of the prosumer;

$P_{t}^{\text {load }}$ is the load of the prosumer;

$P_{t}^{P V}$ is the PV generation.

So, if the prosumer is consuming from the network, $P_{t}^{\text {prosumer }}$ will be associated with the cost of buying energy with the corresponding electricity tariff; similarly, when the prosumer is injecting energy into the network, $P_{t}^{\text {prosumer }}$ will be associated with the corresponding electricity sales price. As previously mentioned, the objective function is to minimize the customer's bill, like the following equation:

$$
f=\sum P_{t}^{\text {prosumer }} \times c_{t}^{\text {prosumer }}
$$

where:

$c_{t}^{\text {prosumer }}$ is the cost of the prosumer energy, if $P_{t}^{\text {prosumer }} \geq 0$ then is the cost of sale energy and if $P_{t}^{\text {prosumer }} \leq 0$ then is the cost of buying energy.

\section{SimULATION RESUlts}

For the simulations a real Portuguese MV distribution network with distributed PV and wind generation was considered. Moreover, it was assumed that there was an aggregation of LV customers with small PV generation units and storage devices at the MV level.

In order to test the proposed approach, a yearly load demand profile, as well as wind and PV generation profiles, were used. These profiles were obtained from the Portuguese energy regulator (ERSE) for the year of 2015. In this case, consumption has an annual demand of $35 \mathrm{MWh} /$ year. For the $\mathrm{PV}$ generation of the aggregate consumer variations, a total of $10 \mathrm{kWp}$ was assumed. Concerning the capacity of the storage devices, it was considered that these could vary from $5 \mathrm{kWh}$ to $100 \mathrm{kWh}$, with $5 \mathrm{kWh}$ increments. The storage devices considered are lithium ions batteries, with a discharge depth (DOD) of 50\%, maximum capacity of charge and discharge is $10 \%$ by hour and $90 \%$ of efficiency. Therefore, several scenarios with different storage capacities have been analysed.

As previously explained, as the algorithm was implemented in MATLAB, all the simulations were also run in MATLAB exploiting the MATPOWER extended OPF framework [5]. The additional constraints and variables presented in the previous section have been included.

The results were obtained taking into account all the variations mentioned above (plus the fact that 1 full year of data was considered), which resulted in a high number of scenarios to be simulated. For this reason, only results from a few days of operation will be presented and commented in the paper. The most interesting days of simulation were selected for the purpose. 
The first results show a day of operation considering a PV generator of $10 \mathrm{kWp}$, located in Porto - Portugal associated to a $10 \mathrm{kWh}$ capacity storage device, with $1 \mathrm{kWh}$ of charge and discharge by hour. This corresponds to the first day of the year which is a typical winter day as shown in Figure 2.

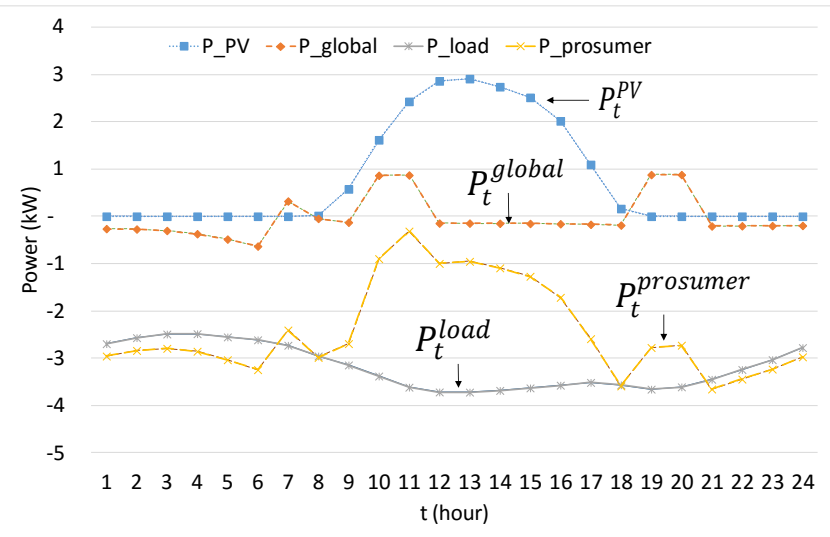

Figure 2 - Operation for one day (10kWp e 10kWh)

It can be observed that the PV generation is able to slightly reduce the energy consumption from the network, but there is no energy surplus that can be injected later into the distribution network. In this case, the role of the storage device is to contribute to reducing the electricity bill since it charges the battery when the energy bought is cheaper and discharges in the period when the energy is more expensive.

Figure 3 presents the results of operation for different day, with a PV generator $10 \mathrm{kWp}$, located in Porto - Portugal, and $10 \mathrm{kWh}$ storage device. This day was chosen since it is a typical summer day with high PV generation.

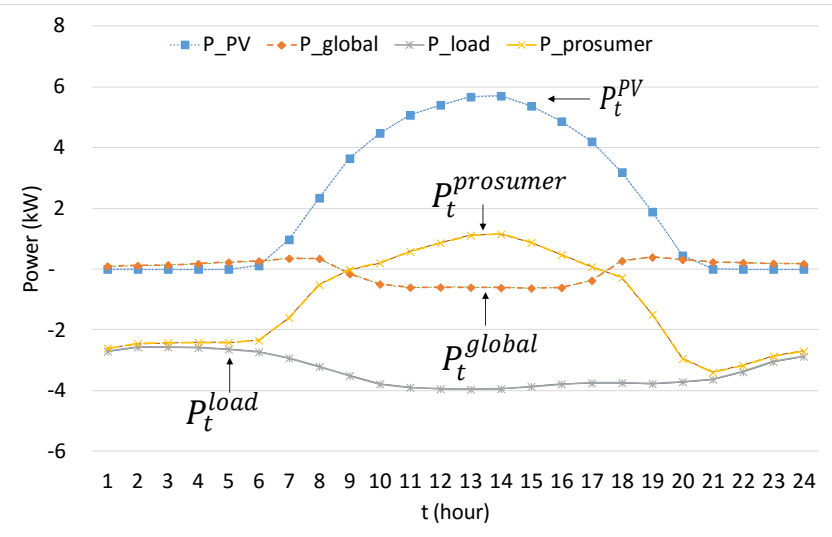

Figure 3 - Operation for another day (10kWp e 10kWh)

Concerning this day of operation, it can be observed that the battery unit does not have enough capacity to store the excess energy from the PV micro-generator, so there is injection of energy into the network in the period from 10 a.m. to 6 p.m. even though the overall objective was to minimize the amount of energy injected into the distribution grid performed (by minimizing the consumer's electricity bill). The storage device was used respecting the SOC thresholds defined as well as the charging and discharging limits in each hour.
Figure 4 shows the storage device SOC for the day of operation shown in Figure 3. Note that the battery was charged up to the limit of its maximum capacity. In the end of the day the SOC returned to the initial value, as it was assumed (in this case $\mathrm{SOC}=80 \%$ ).

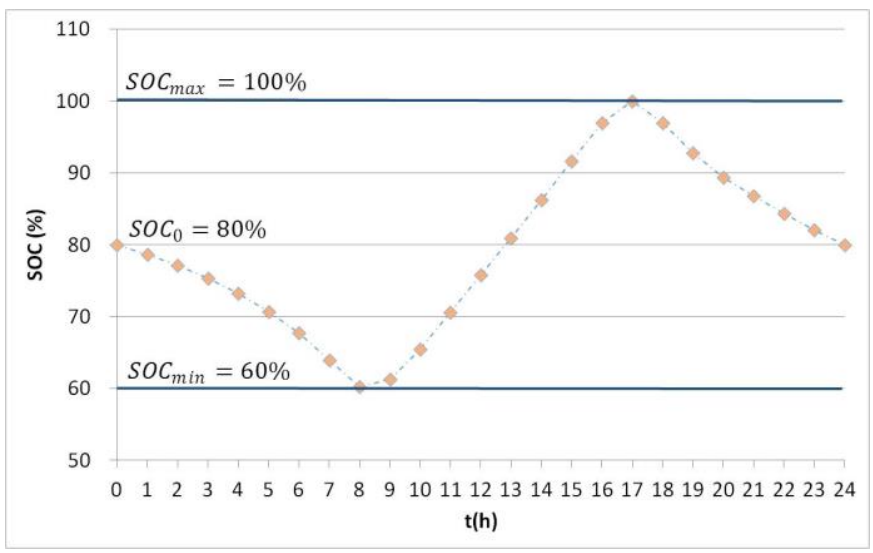

Figure 4 - State of Charge (10kWp e 10kWh)

Figure 5 shows the results of operation for another day, with $10 \mathrm{kWp}$ of PV generation in the Porto City, Portugal but now considering a storage device with $30 \mathrm{kWh}$ of capacity.

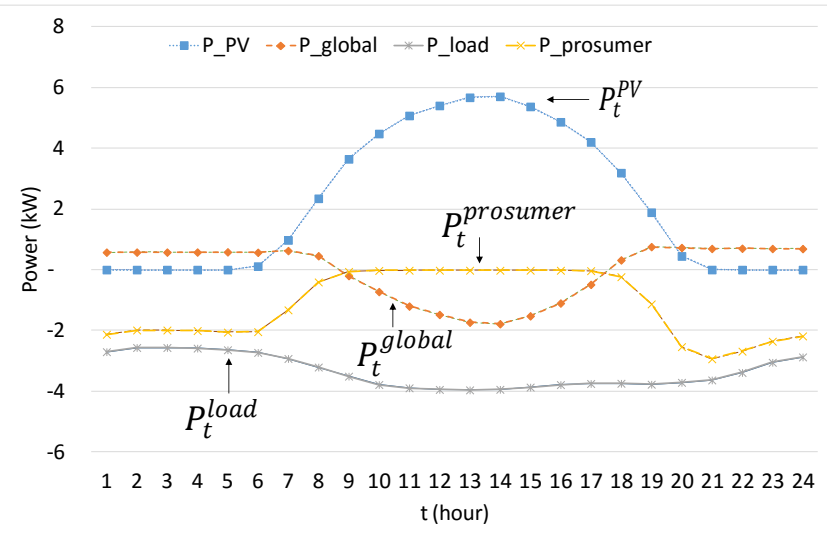

Figure 5 - Operation for one day (10kWp e 30kWh)

In this case, it is possible to observe that the storage device has now sufficient capacity to store the excess energy from the PV panels, thus avoiding the injection of energy into the distribution network. It can also be seen that the highest consumption period is where the energy purchased from the grid is cheaper, by charging the storage device, that it is then discharged during the period of more expensive energy price.

From the results obtained, it is possible to see that the storage devices are an interesting alternative to the smoothing of the load consumption curve, having an important role in reducing consumption for consumers who have their own generation associated with storage devices.

\section{FINANCIAL VIABILITY ANALYSIS}

This section presents the financial analysis for the viability of the installation of PV systems together with storage devices at residential customers in order to smooth the energy demand 
from the distribution network and improve usage of energy produced at the customer's premises.

For the financial analysis an aggregated consumption of LV customers at the MV level was considered with annual demand of $35 \mathrm{MWh}$, and two possible PV generation systems with capacity $10 \mathrm{kWp}$ and $15 \mathrm{kWp}$ and four combination of storage devices like $5 \mathrm{kWh}, 10 \mathrm{kWh}, 20 \mathrm{kWh}$ and $30 \mathrm{kWh}$. The results from a full year of simulation were obtained by the running the multi-temporal OPF for each day of one full year, considering the last SOC of one day as the initial SOC for the next day.

The analysis was performed considering the commercialization rate, the average monthly price of energy Iberian market operator, as well as annual load data and the annual generation for each hour from the Portuguese regulator for the full year of 2015. Furthermore, an annual update on the purchase price and the energy sale price by $2.5 \%$ due to the tariff deficit was considered, similarly to the work presented in [9].

The current value for the price of lithium-ion batteries considered is around $500 € / \mathrm{kWh}$. However, it is expected that in the near future the prices for these batteries can drop to a value of around $200 € / \mathrm{kWh}$. Therefore, several scenarios with different costs between this range were considered in order to view the rates of return of the investment in different situations.

The financial analysis was carried out for a 12-year and a 20 -year analysis horizons. For the analysis of the 20-year horizon it was considered that the replacement of the batteries would occur at the beginning of year 13 due to the life expectancy considered for this storage technology.

TABLE III. IRR FOR INVESTING IN PV + STORAGE

\begin{tabular}{|c|c|c|c|c|}
\hline \multirow{2}{*}{$\begin{array}{c}\text { Storage } \\
\text { Device } \\
(\mathbf{E} / \mathbf{k W h})\end{array}$} & \multicolumn{2}{|c|}{$\mathbf{1 0 k W p}-\mathbf{5 k W h}$} & \multicolumn{2}{|c|}{ 10kWp- 30kWh } \\
\cline { 2 - 5 } & \multicolumn{4}{|c|}{ Analysis Horizon } \\
\hline $\mathbf{2 0 0}$ & $\mathbf{1 2}$ years & $\mathbf{2 0}$ years & $\mathbf{1 2}$ years & $\mathbf{2 0}$ years \\
\hline $\mathbf{2 5 0}$ & $9,92 \%$ & $13,85 \%$ & $6,81 \%$ & $10,52 \%$ \\
\hline $\mathbf{3 0 0}$ & $9,65 \%$ & $13,58 \%$ & $5,68 \%$ & $9,34 \%$ \\
\hline $\mathbf{3 5 0}$ & $9,38 \%$ & $13,32 \%$ & $4,64 \%$ & $8,25 \%$ \\
\hline $\mathbf{4 0 0}$ & $8,86 \%$ & $13,06 \%$ & $3,70 \%$ & $7,22 \%$ \\
\hline $\mathbf{4 5 0}$ & $8,60 \%$ & $12,81 \%$ & $2,82 \%$ & $6,24 \%$ \\
\hline $\mathbf{5 0 0}$ & $8,36 \%$ & $12,56 \%$ & $2,01 \%$ & $5,32 \%$ \\
\hline
\end{tabular}

Table III presents the results for the Internal Rate of Return (IRR) for all the scenarios that were simulated cases as described in the previous paragraphs. In this case, a value of $8 \%$ IRR was considered as being a sufficiently attractive rate. As can be observed, for the system with $5 \mathrm{kWh}$ storage capacity and considering a 20-years horizon of analysis, the investment can be considered viable. For storage devices with greater capacity, only when the price of storage devices drops to values below $350 € / \mathrm{kWh}$ and considering a 20 -year analysis horizon does this solution becomes economically feasible.

\section{CONCLUSIONS}

Using the proposed methodology, it is possible to conclude that storage devices can be regarded as a good alternative for the management of PV systems within a self-consumption scheme. The storage devices are used to shift the load curve of the prosumer by consuming energy previously stored in hours where the electricity price is higher. The proposed multitemporal OPF formulation has been evaluated though simulation in a real test case and revealed a good performance of the algorithm.

A financial viability analysis was also performed taking into account a horizon of 20 -year life horizon. Usually the financial analysis for this type of projects would be performed for the period of the life span of the battery, i.e. around 12 years. However, here we consider that the battery is replaced in year 13 in order to extend this analysis. This makes the analysis more attractive in terms of investment, by enabling the overall project. Moreover, it is seen that a battery system with small capacity is viable. In fact, considering that the investment cost in these types of systems is expected to drop substantially in the future, the possibility of having larger capacities associated to the storage may also become attractive from an investment perspective.

\section{ACKNOWLEDGMENTS}

This work is financed by the ERDF - European Regional Development Fund through the Operational Programme for Competitiveness and Internationalisation - COMPETE 2020 Programme within project «POCI-01-0145-FEDER-006961», and by National Funds through the FCT - Fundação para a Ciência e a Tecnologia (Portuguese Foundation for Science and Technology) as part of project UID/EEA/50014/2013."

\section{REFERENCES}

[1] A. Madureira, C. Gouveia, C. Moreira, L. Seca, J. Peças Lopes, "Coordinated management of distributed energy resources in electrical distribution systems", in IEEE PES Innovative Smart Grid Technologies Latin-America (ISGT LA), Sao Paulo, 2013, pp. 1-8.

[2] C. J. C. Williams, J. O. Binder, T. Kelm, "Demand side management through heat pumps, thermal storage and battery storage to increase local self-consumption and grid compatibility of PV systems", in 2012 3rd IEEE PES Innovative Smart Grid Technologies Europe (ISGT Europe), Berlin, 2012, pp. 1-6.

[3] M. Castillo-Cagigal, E. Caamaño-Martín, E. Matallanas, et al., "PV self-consumption optimization with storage and Active DSM for the residential sector", Solar Energy, vol. 85, no. 9, pp. 2338-2348, 2011.

[4] M. Heleno, D. Rua, C. Gouveia, et al., "Optimizing PV selfconsumption through electric water heater modeling and scheduling", in IEEE PowerTech 2015, Eindhoven, 2015, pp. 1-6.

[5] R. D. Zimmerman, C. E. Murillo-Sánchez, and R. J. Thomas, "Matpower: Steady-State Operations, Planning and Analysis Tools for Power Systems Research and Education", IEEE Transactions on Power Systems, vol. 26, no. 1, pp. 12-19, 2011.

[6] J. Nocedal, S.J. Wright "Numerical Optimization", Springer Series in Operations Research, Springer 2006.

[7] V.H. Quintana, G.L. Torres, J. Medina-Palomo, "Interior-point methods and their applications to power systems: a classification of publications and software codes", IEEE Transactions on Power Systems, vol. 15, no. 1, pp. 170-176, 2010.

[8] M. Liu, S. K. Tso, Y. Cheng “An Extended Nonlinear Primal-Dual Interior-Point Algorithm for Reactive Power Optimization of LargeScale Power Systems with Discrete Control Variables", IEEE Transactions on Power Systems, vol. 17, no. 4, pp. 982-991, 2002.

[9] EDP Produção, Tecnologias de Armazenamento de Energia e seu potencial para os sistemas elétricos, in Portuguese, Portugal: EDP Produção, 2015, p. 304. 